\title{
Registros da paisagem urbana em algumas leituras visuais e escritas: capturas sensiveis e os espaços da(s) cidade(s)
}

Urban landscape records in some visual and written readings: sensitive captures and spaces(s) of town(s)

Los registros del paisaje urbano en algunas lecturas visuales y escritos: capturas y espacios sensibles(s) ciudad(s)

Ana Heloisa Molina*

\section{Resumo}

O texto intenta analisar a complexidade do conceito de cidade, suas transformações e as apropriações realizadas por seus habitantes. Com base na seleção de documentos visuais e escritos, em diversos recortes de tempo e espaço, busca incitar as percepções de tais "janelas" como possibilidades de informação. Procura instigar capturas sensíveis, baseando-se nos registros selecionados e possibilitar outras reflexões acerca desses espaços em reelaboração contínua. Circunscrevemos alguns espaços e tempos como cápsulas de observação no intuito de verificar as mudanças ocorridas no espaço urbano e a apreensão em vários registros visuais ou escritos: Porto Alegre (RS), Paris (França), Rio de Janeiro (RJ), Salvador (BA), Feira de Santana
(BA), Recife (PE), Welwyn Garden City (Inglaterra) e Itabira (MG), do final do século XIX até meados do século XX.

Palavras-chave: Cidade. Registros. Sensibilidades.

Doutora em História pela Universidade Federal do Paraná, Brasil. Professora do Departamento de História e do Programa de Pós-Graduação em História Social da Universidade Estadual de Londrina, Brasil. E-mail: anaheloisamolina@yahoo.com.br

Recebido em 01/04/2016 - Aprovado em 01/09/2016 http://dx.doi.org/10.5335/hdtv.16n.2.6924 


\section{Introdução}

Elaborar um conceito sobre cidade é tão complexo quanto tentar capturá-la em suas variadas facetas ao longo de um recorte de tempo. Seccioná-la em registros visuais, literários e de relatos é uma possibilidade interessante, pois tais perspectivas propõem também questões relacionadas à memória, à ideia de pertencimento e à transformação do espaço em um lugar embebido de sentimentos e sentidos.

Este texto levanta algumas considerações, entre tantas outras possíveis, sobre perceber a paisagem urbana e sua relação com as transformações provocadas por diferentes ações, injunções e conjunturas estruturais, históricas e humanas vivenciadas pela cidade. Paralelamente procura refletir sobre os registros, as referências visuais e textuais pinçados de diversos tempos e espaços enquanto artefatos históricos, na captura dos fragmentos que apontam as diversas cidades possíveis de habitar uma mesma cidade.

Circunscrevemos alguns espaços e tempos como cápsulas de observação no intuito de verificar as mudanças ocorridas no espaço urbano e a apreensão em vários registros visuais ou escritos: Porto Alegre (RS), Paris (França), Rio de Janeiro (RJ), Salvador (BA), Feira de Santana (BA), Recife (PE), Welwyn Garden City (Inglaterra) e Itabira (MG), do final do século XIX até meados do século XX.

\section{Cidade, cidades: espaço e lugar}

A cidade é o espaço da liberdade e nela respira-se o ar da liberdade. Tal premissa acompanha a concepção de cidade desde a Idade Média. É também, tradicionalmente o lócus da cultura, contrapondo-se à natureza rústica do território rural.

[...] Civismo e civilização, urbanidade e urbano são parentes próximos, e opõem-se à rusticidade. Esta posição privilegiada não é exclusiva da grande cidade, que, muito pelo contrário, suscita juízos contraditórios, mas sim em primeiro lugar da cidade de médias dimensões que, tanto na prática como nas intenções, se diferencia do contexto territorial rural, embora nele defina perfeitamente o seu lugar próprio (RONCAYOLO, 1986, p. 422).

O processo de urbanização crescente, em seus desníveis e peculiaridades regionais, promoveu ambiguidades no tocante à introdução de novas técnicas e tecnologias e às apropriações pelos seus habitantes e dessa forma implantou-se novo modelo cultural diante da tradições instituídas anteriormente especialmente em meados do século XIX e no início do século XX.

O constante jogo tradição/inovação, valores morais/valores técnicos, arcaísmo/ modernidade reflete as tensões e conflitos que se desenrolam no espaço da cidade, onde a precisão de um contexto histórico é necessária para sua devida análise.

$\mathrm{Na}$ cidade, produziu-se o indivíduo moderno com novos e intensos contatos e confrontos, o indivíduo livre das relações tradicionais. Se a cidade é o espaço da liberdade, é também o espaço da fragmentação, da heterogeneidade. Foi ainda na cidade que se construiu um sistema de controle, de disciplinarização desse indivíduo moderno. Há assim uma representação contraditória nesse novo espaço social. De um lado, atração e sedução, expressas nas palavras luz, Meca da cultura e da civilização, de outro, repúdio e rechaço, contidos nas noções de ameaça, de centro de perdição, de império 
do crime e da barbárie, quando das transformações urbanas na virada do século XIX e início do século XX (OLIVEIRA, 2000).

Simultaneamente campo de organização e de desorganização, a cidade se readapta em ritmo constante, como espaço de práticas sociais e representações, pautado em outras referências de tempo e espaço, fragmentação e heterogeneidade, tradições e novidades, memórias e silêncios ou amnésias, em um processo seletivo nem sempre inteligível.

Nesse espaço, define-se a "legibilidade" de suas marcas físicas, visualmente reconhecidas, organizadas e apreendidas pelos seus habitantes. Mapas físicos e cartografias sentimentais riscam esses espaços, mesclando tempos.

Escolhemos um poema de Mário Quintana (1906-1994), poeta, tradutor e jornalista, apaixonado por Porto Alegre e pelo Rio Grande do Sul para pensarmos como, com base no lirismo, é possível compor reflexões sobre os mapas e as ruas de uma cidade em constante movimento e transformação.

O mapa

Olho o mapa da cidade Como quem examinasse A anatomia de um corpo... (É nem que fosse o meu corpo!)

Sinto uma dor infinita

Das ruas de Porto Alegre

Onde jamais passarei...

Há tanta esquina esquisita, Tanta nuança de paredes, Há tanta moça bonita Nas ruas que não andei (E há uma rua encantada Que nem em sonhos sonhei...) (QUINTANA, 2012, p. 67).
As imagens de "esquinas esquisitas" "nuança de paredes" e "ruas encantadas" são fragmentárias e nada possuem de neutralidade, construídas pelos habitantes ou pelo poeta com base em sua experiência, imaginários e memória.

A imagem da cidade já não depende, a priori, de uma concepção global, é parcial, construída a partir de seqüências simultaneamente topográficas e temporais (nomeadamente seqüências de deslocação), diversa e desigualmente ampla segundo os grupos (RONCAYOLO, 1986, p. 478).

Esse conjunto de percepções, cujo conteúdo permanece visual ou propõe uma narrativa visual faz com que a cidade-orientação permaneça uma cidade-espetáculo em constante reencenação que, a cada instante, transforma-se em outras cidades-imagens.

O processo de significação imagético é complexo e depende de diferentes repertórios dos usuários urbanos em leituras individuais subjetivas e muitas vezes contraditórias.

A imagem de uma cidade não se define apenas pelo que se vê, já que nela podem estar contidas lembranças e significações particulares e/ou de grupos. [...] A leitura não é objetiva porque existem momentos de subjetividade, já que vivemos as imagens de uma cidade dando-lhes sempre a nossa interpretação particular (OSTERMANN, 1996, p. 163).

As percepções são estabelecidas em um jogo complexo em que os signos e suas representações permitem alocar múltiplos valores, eventualmente contraditórios. As referências estéticas e materialidades eleitas colocam-se como sinais de (des)identificação individuais e coletivas. 
As cidades são, antes de tudo, uma experiência visual. Traçado de ruas, via de circulação ladeada de construções, os vazios das praças cercadas por igrejas e edifícios públicos, o movimento de pessoas e a agitação das atividades concentradas em um mesmo espaço estão saturadas de significações acumuladas através do tempo, produções sociais relacionadas a uma forma de inserção topográfica ou particularidade arquitetônica.

[...] Pontos de referência para o leitor, mas também algo relacionado à permanência das formas do traçado urbano e das edificações, ou mesmo da sua rápida transformação, fazem da materialidade dos núcleos urbanos um suporte da memória, recorte preciso com contornos apreensíveis, capaz de orientar o conhecimento ou o reconhecimento dos que por elas passam ou nelas moram (BRESCIANI, 1998, p. 237-238).

Essas variantes promovem graus psicológicos de percepção e de análise das condições sociais do comportamento, que se modificam nas novas reinserções de espaço dessa cidade, que se avolumam e impõem outros ritmos.

Georg Simmel (1858-1918), em sua análise da vida na metrópole, aponta as atitudes de introversão ou por outro lado, blasé, como escudos à alta frequência da polifonia nesse espaço que se quer lógico, voraz, anônimo e nivelador e, assim, frustrante. Escrito em 1902, A metrópole e a vida mental analisa cada atravessar de rua como o ritmo e a multiplicidade da vida econômica intensificam os problemas da vida moderna, a luta da individualidade contra as forças históricas, culturais e ocupacionais. Ocorre um contraste profundo com a vida de cidade pequena e a vida rural no que se refere aos fundamentos sensoriais da vida psíquica. Diz o autor:

[...] Não há talvez fenômeno psíquico que tenha sido tão incondicionalmente reservado à metrópole quanto a atitude blasé. A atitude blasé resulta em primeiro lugar dos estímulos contrastantes que, em rápidas mudanças e compressão concentrada, são impostos aos nervos. [...] Isto constitui aquela atitude blasé que, na verdade, toda criança metropolitana demonstra quando comparada com crianças de meios mais tranqüilos e menos sujeitos a mudanças. Essa fonte fisiológica da atitude blasé metropolitana é acrescida de outra fonte que flui da economia do dinheiro. A essência da atitude blasé consiste no embotamento do poder de discriminar. Isto não significa que os objetos não sejam percebidos, como é o caso dos débeis mentais, mas antes que o significado e valores diferenciais das coisas, e daí as próprias coisas, são experimentados como destituídos de substância. Elas aparecem à pessoa blasé num tom uniformemente plano e fosco; objeto algum merece preferência sobre outro (SIMMEL, 1973, p. 15-16).

Pinturas de movimentos artísticos no final do século XIX e nas primeiras décadas do $\mathrm{XX}$ nos auxiliam a detectar as mudanças ocorridas nos espaços físicos e também nas atitudes/comportamentos dos citadinos nessa nova configuração.

Capturando as impressões promovidas pela velocidade, eletricidade, luzes (palavras-chave da modernidade) e o vai e vem de pessoas, bondes, carruagens e carros tais telas flagram o aturdimento e, ao mesmo tempo, o encantamento e a dispersão do homem moderno transitando em suas novas configurações de "passagens", como nos alerta Benjamin (1996). 
Lembramos que analisar o documento visual "pintura" exige alguns cuidados com relação à autoria, ao movimento artístico filiado, ao contexto histórico, às técnicas artísticas utilizadas, às dimensões do quadro, às legendas construídas ou não pelos pintores, ao tema apresentado e sua estrutura, ao enquadramento, entre outros aspectos.

Devido às dimensões deste artigo, situaremos rapidamente os pintores selecionados e apresentamos suas obras e algumas pistas de observação sem aprofundar as potencialidades de exploração de informações dessas imagens, que, no entanto, nos fornecem indícios preciosos.

Camille Pissarro (1830-1903), pintor francês, cofundador do impressionismo no final do século XIX, desenvolveu uma vasta obra com registro de paisagens rurais e urbanas. Nos anos 1890, abandonou gradualmente o neoimpressionismo, preferindo um estilo mais flexível, que melhor lhe permitisse captar as sensações da natureza, ao mesmo tempo em que explorou a alteração dos efeitos da luz, tentando também exprimir o dinamismo da cidade moderna, dos quais são exemplos os vários quadros que pintou com vistas de Paris, como o que se pode observar na Figura 1, a seguir.
Figura 1 - Boulevard Montmartre, Tarde na chuva, 1897 - óleo canvas, $52,5 \mathrm{~cm} \times 66 \mathrm{~cm}$, Camille Pissarro (1830-1903)

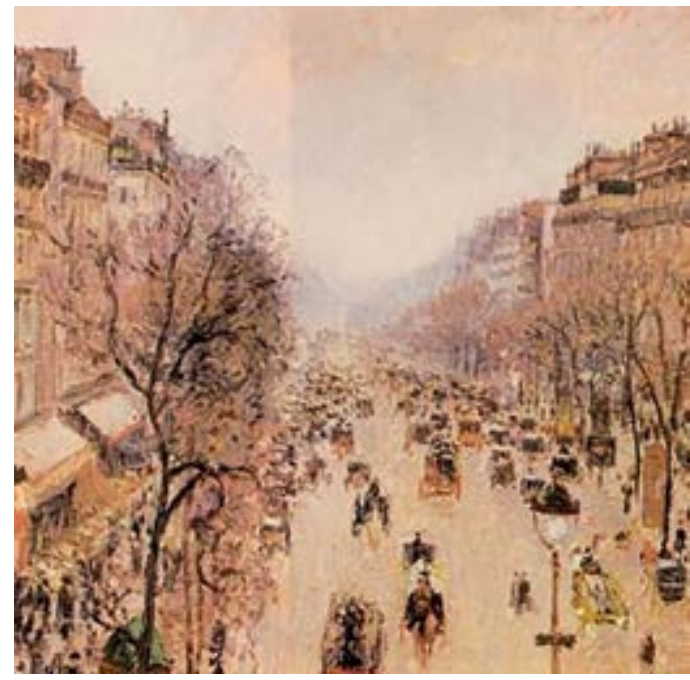

Fonte: <www.hermitagemuseum.org/wps/portal/hermitage/ digital-collection/01.+Paintings/28682/?lng=>.

Gustave Caillebotte (1848-1894) nasceu em uma família muito rica, que fez sua fortuna na indústria têxtil e, em seguida, no negócio imobiliário, quando o Barão Haussmann, o "artista demolidor", reconstruía Paris, entre 1853 e 1870. Especializou-se em pintar vistas dessa cidade e de seus arredores, assim como imagens da vida da classe trabalhadora. Zola, que tomará partido dos impressionistas rejeitados pela crítica e recusados pelo júri do Salão de Arte, será crítico em relação a Caillebotte, de quem vai denunciar realismo "fotográfico" no momento da segunda exposição impressionista. Esse realismo "fotográfico" pode ser apreciado no registro do quadro que segue, a circulação de pessoas em um dia chuvoso nas ruas de Paris (Figura 2). 
Figura 2 - Paris em dia chuvoso, 1877 - óleo sobre tela, 2,39 m x 1,85 m, Gustave Caillebotte (1848-1894)

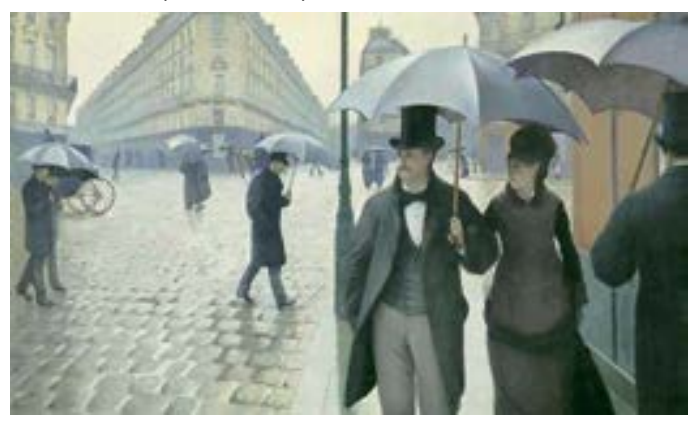

Fonte: </br.pinterest.com/pin/472878029594101597/>.

George Grosz (1893-1959) era pintor e desenhista alemão. Destacou-se, inicialmente no movimento Dadá, em Berlim, de 1917 a 1920. Grosz sintetiza duas tradições distintas e de longa data dentro da história da arte alemã para criar seu estilo único. Combinando qualidade linear da tradição gráfico histórico com propensão da arte gótica alemã para imagens grotescas, Grosz utilizou esses modos tradicionais para enfatizar sua perspectiva moral. Foi um dos principais membros do grupo expressionista da Nova Objetividade, empenhando-se em analisar criticamente a situação política e social da Alemanha, durante a República de Weimar (1919-1933). O quadro escolhido (Figura 3) sugere-nos o ritmo frenético da cidade, suas cores cintilantes, seus letreiros chamativos e o passo rápido, insensível e atropelado de seus habitantes.
Figura 3 - A cidade, 1917 - óleo sobre tela, $100 \mathrm{~cm} \mathrm{x}$ $102 \mathrm{~cm}$, George Grosz (1893-1959)

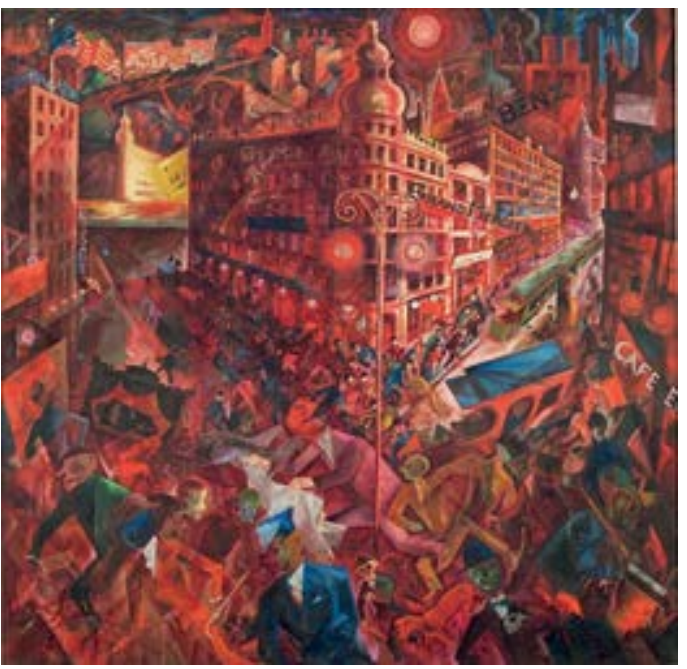

Fonte: <http://extensao.cecierj.edu.br/material_didatico/ artc1701/galeria_Grosz.html>.

Os três pintores e seus quadros nos propõem diversas questões e enfatizam a ação dos novos espaços e das reformas urbanas enquanto um personagem a ser decifrado e vivenciado pelos seus habitantes: transeuntes, flâneurs, boêmios, burgueses e novos ricos transitam em boulevares e cafés, ruas e avenidas, observam vitrines, adotam novas etiquetas, vestem novos toilettes (e respectivos acessórios para mulheres e homens) e abraçam trejeitos em uma performance adequada aos tempos modernos. Podemos pensar tais questões, propostas nas reformas urbanas na virada do século XIX para o XX, em outros suportes visuais que incitem o debate acerca das transformações dos espaços.

A fotografia em seu nascimento no século XIX e desenvolvimento no século XX adota diversos procedimentos oriundos da pintura como o enquadramento do tema, o 
jogo claro/escuro, a perspectiva de janela entre outros processos. Em sua busca por autonomia, desvinculando-se das técnicas artísticas da pintura, arroga-se como recorte de realidade, já que seu registro é mediado pela máquina e pelo olho humano. Tal perspectiva, como espelho, reflexo e realidade, foi aceita e vigorou por muito tempo.

As fotografias necessitam de um tratamento próprio, pois, como matéria do conhecimento histórico, propõem um novo tipo de ver e dar a ver diversos olhares do e sobre o mundo moderno.

Dar a ver é sempre inquietar o ver, em seu ato, em seu sujeito. Ver é sempre uma operação de sujeito, portanto uma operação fendida, inquieta, agitada, aberta. Entre aquele que olha e aquilo que é olhado (DIDI-HUBERMAN, 1998, p. 77).

No entanto, as fotografias integram um sistema de significação que não pode ser reduzido ao nível das crenças formais e conscientes, elas pertencem também à ordem do simbólico e da linguagem metafórica, pois, em vez de representar, capta

[...] forças, movimentos, intensidades, densidades, visíveis ou não; e não para representar o real, porém para produzir e reproduzir o que é passível de ser visível (não o visível) (ROUILLÉ, 2009, p. 36, grifo do autor).

Compreender as particularidades da natureza da linguagem fotográfica significa eleger ferramentas teóricas próprias que abarcam um sistema de símbolos, metáforas e estilos cognitivos que, por sua vez, dialogam com o momento histórico de seu contexto, portador de um olhar criador, desenvolvido, moldado ao seu tempo e espaço, no qual o fotográfico é um estado do olhar e um ato, lugar que promove uma negociação silenciosa da imagem como um produto dado para ser visto (construção do autor) quanto para a leitura do espectador (desconstrução) (SAMAIN, 2005).

Partimos do pressuposto de que as fotografias enquanto documentos nos auxiliam a tomar contato com a cultura de um determinado tempo e lugar e nos instiga a indagar como e por que a memória coletiva organiza visualmente grupos sociais, paisagens e fatos de uma mesma sociedade, como e por que esse imaginário social criado pela circulação de imagens reforça certas visões de mundo em outros circuitos, como os educacionais ou midiáticos, por exemplo. Temos também que tomá-las enquanto documento e registro anotando a autoria, o ano, o contexto histórico, as técnicas utilizadas, o enquadramento, as referências internas e externas, o acervo e a guarda, entre outros dados.

Selecionamos três fotografias, com datas entre meados do século XIX e início do XX (Figuras 4 a 6), para pensarmos a seleção, o enquadramento, o protagonismo da rua, do equipamento urbano, as ideias de progresso e civilização, com os bondes, as fachadas comerciais e a iluminação tão caras àquele momento, e o movimento das pessoas em cidades diferentes, que sofriam as metamorfoses de seu traçado: Feira de Santana, BA, Paris (França) e Rio de Janeiro, RJ, com o intuito de atentar para as possibilidades de apreensão das mudanças e dos registros realizados. 
Figura 4 - Bondes na Praça da Alfandega, 1885, Feira de Santana, BA, autor desconhecido

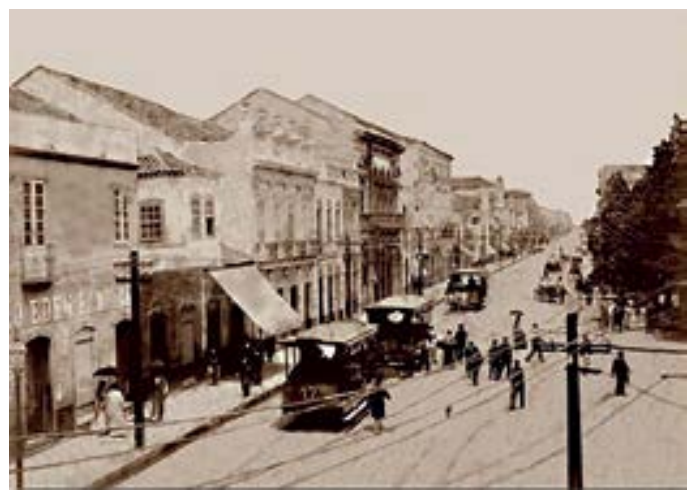

Figura 5 - Place Saint-André-des-Arts, ca. 1865, Paris (França), Charles Marville (1813-1879)

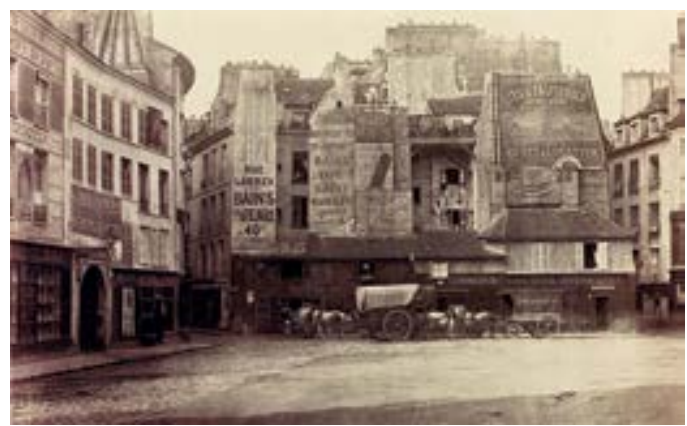

Fonte: <https://br.pinterest.com/dickverroen/foto-marville-charles-1813-1879/>.

Figura 6 - Rio de Janeiro depois de Francisco Pereira Passos, (1910, circa), Marc Ferrez (18431923)

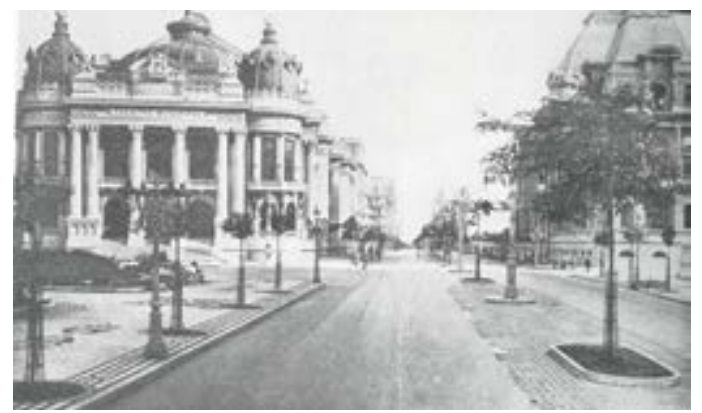

Fonte: <http://brasilianafotografica.bn.br/brasiliana/discover?s cope $=\% 2 F \&$ query $=$ Rio + de + Janeiro + Marc + Ferrez\&su bmit $=\mid r>$.
Na era moderna, as cidades são locais e moto de mudança e seus ambientes são propícios à experimentação diversa em expressões individuais e coletivas. Na Europa, projetam-se, desde 1880, planos de urbanização e de modernização exportados em modelos de planejamento espacial que propõem outras diretivas sociais, culturais e políticas do uso do lócus urbano.

[...] A cidade, fato cultural, mas seminaturalizado pelo hábito era pela primeira vez o objeto de uma crítica radical. Tal questionamento não podia deixar de chegar a uma interrogação sobre os fundamentos. A presença da cidade foi então substituída por idéia sua. E, depois de ter qualificado como desordem a ordem urbana existente, foram feitos esforços para opor-lhe ordens ideais, modelos, que são, com efeito, projeções racionalizadas de imaginários coletivos e individuais (CHOAY, 1992, p. 50).

Podemos citar entre esses idealizadores, Ildefonso Cerdá y Sunyer (1815-1876), arquiteto e engenheiro, autor da proposta do plano de extensão de Barcelona (1857) e idealizador da Teoria General de la Urbanización, em 1867. Ele propunha nesse tratado a palavra urbanização, que designaria tanto "um conjunto de ações tendendo a agrupar as construções e regularizar seu funcionamento", como

[...] um conjunto de princípios, doutrinas e regras que é preciso aplicar para que as construções e seu agrupamento contribuam para favorecer seu [do homem social] desenvolvimento, assim como, aumentar o bem-estar individual e a felicidade pública (CERDÁ, 1867 apud VASCONCELOS, 1999, p. 45).

Outro profissional que pensou distintamente a cidade, entre tantos planejadores 
urbanos, foi Ebenezer Howard (1850-1928), criador das cidades-jardins com sua obra de 1898, Tomorrow: a peaceful path to social reform, cujas características essenciais são: área circular cercada por um cinturão verde, limitada por uma linha férrea, rodovias radiais que saem do parque central, dividindo a cidade em seis setores, localização do parque junto às escolas e igrejas, sistema rodoviário que irradia do centro, interceptando vias circulares para os movimentos transversais, integração do conjunto de cidades feita por um sistema intermunicipal de linhas férreas com o objetivo de otimizar o trânsito.

Algumas dessas ideias foram adotadas, em tempos distintos, para o planejamento de cidades brasileiras como Goiânia, GO, e Maringá, PR.

A proposta de cidade-jardim publicada por Ebenezer Howard em 1902 sob o título Garden Cities of Tomorrow não se referia a um modelo espacial e sim a um esquema teórico de uma cidade autônoma, de gestão comunitária, de dimensão limitada por extensa faixa agrícola que a circundava e que, caracterizada por altas taxas de áreas verdes, seria uma alternativa para o caos e decadência urbanos da Inglaterra do final do século XIX. Howard (1996), menos interessado e envolvido com as questões próprias do desenho urbano, talvez pela sua própria formação, estava mais empenhado numa solução para o problema urbano que proporcionasse moradia digna para as classes trabalhadoras. Deste modo, apresenta não uma forma urbana, mas um diagrama de assentamento para 32.000 habitantes em sua área urbana de 400 hectares e 2.000 habitantes em terrenos agrícolas, ocupando 2.020 hectáres. O esquema da cidade apresentada no diagrama, que Howard (1996) enfatizou não se tratar de plantas definitivas, mas de um conceito que a realidade, com suas peculiaridades geográficas, daria a configuração definitiva, consistia em estrutura circular dividida em seis setores. Estes setores seriam delimitados por seis bulevares arborizados, com 36 metros de largura, que se irradiariam desde o parque central e se estenderiam até o perímetro externo, circundado pela ferrovia que, após envolver a cidade, se transformaria em estrada de penetração no ambiente rural. Completariam a estrutura viária da Cidade Jardim cinco avenidas, também arborizadas, concêntricas ao Parque Central (REGO, 2001, p. 1569-1570), como demonstrado na Figura 7.

Figura 7 - Vista aérea da segunda cidade-jardim da Inglaterra, fundada em 1920, Welwyn Garden City, no condado de Hertfordshire

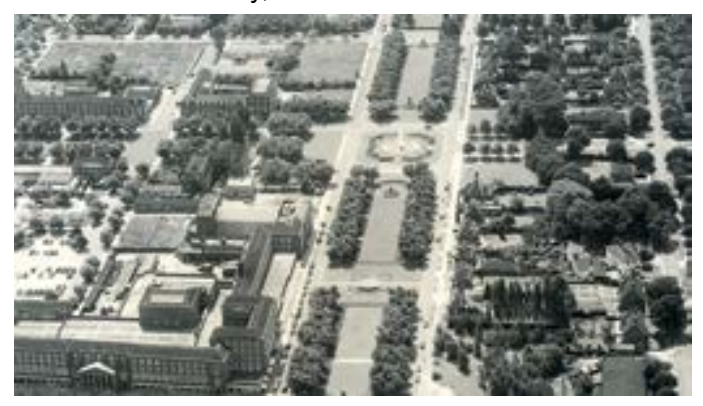

Fonte: <http://www.cbll.com.br/materia/o-conceito-britanico-de-cidades-jardins-no-brasil/>.

Com significado complexo, a cidade assume um papel de mediação incerta e essa postura ambivalente detona mecanismos de crítica ou olhares menos românticos de suas virtudes, com os quais a sátira ou a visão ingênua do interiorano desnuda seus aspectos não tão perfeitos. Aponta assim a ação de seus habitantes que incorrem em pequenas 
subversões ou desobediências, desenhando outros caminhos ou utilizando/apropriando-se dos espaços de outras maneiras.

As ruas são traçadas visando dar maior fluxo à multidão que transita. Espaço público por excelência, também é o local do anonimato, instaurador de outro olhar e definidor de outros usos, estabelece e produz vias e percursos de trânsito diário e rotineiro, de festas populares, procissões religiosas, enterros solenes, desfiles e intercâmbios diários da população, em um sentido de ver e ser visto, para ver e ser perdido. Movimento de pessoas, carros e animais traduzia a ascensão da vida urbana e o sentimento de modernidade, como podemos perceber na Figura 8 no cortejo de festejos em Paris em 1908.

Figura 8 - Cortejo da terça-feira gorda na rue Secrétan, 1908

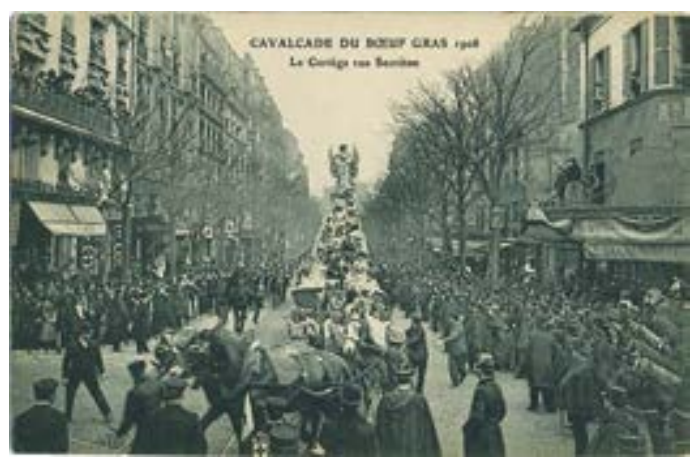

Fonte: <https://commons.wikimedia.org/wiki/File:Le_ Boeuf_Gras_\%C3\%A0_Paris,_26_avril_1908,_rue_Secr\%C3\%A9'tan.jpg>.

A multidão era tamanha que, no fim do século XIX e no início do século XX, a circulação de veículos era interrompida nos Grands Boulevards na terça-feira gorda e na quinta-feira da Quaresma em Paris.

O novo traçado estabelece uma ideia de performance social ao indicar os espaços e locais a serem frequentados, o que sugere uma reordenação social subliminar, normatizando hábitos e promovendo uma fúria avassaladora de embelezamento, conforto, segurança e higiene.

Portadora, pois, de uma nova identidade, cartão de visitas de uma cidade, a rua nova foi retratada pelo olhar de pintores, escritores, jornalistas, poetas e fotógrafos (PESAVENTO, 1996, p. 10).

Essas representações tornam-se objetos de desejo e consumo, como cartões-postais, por exemplo, nos quais o fragmento do olhar flagra e promove um recorte desejado e desejável, souvenir de viagem, lembrança de um instante, congelamento de uma experiência vivenciada por meio da viagem, um recorte de construção da imagem organizada e selecionada de um espaço e de um modo de viver.

[...] o cartão-postal pode ser entendido como o início do processo de globalização por meio da imagem de um mundo que se internacionalizava pelo crescimento do comércio e dos fluxos migratórios. O postal promoveu a democratização da imagem fotográfica garantindo para as gerações futuras acesso a uma memória que poderia ter sido facilmente descartada (FERNANDES JÚNIOR, 2002, p. 17 apud FRANCO, 2006, p. 26).

Os cartões-postais (Figuras 9 e 10) apresentam uma fração dos projetos de urbanização de Paris no final do século XIX e as releituras desse movimento nas cidades brasileiras, cuja proposta era salientar a melhor imagem do país e transmitir a ideia de modernidade por intermédio da implantação de infraestrutura urbana compatível com os países desenvolvidos do mundo, como no caso de Recife, PE, a Paris do Nordeste. 
Figura 9 - Paris, Les grands cafés des boulevards, postal ilustrado de Paris (França), final do século XIX

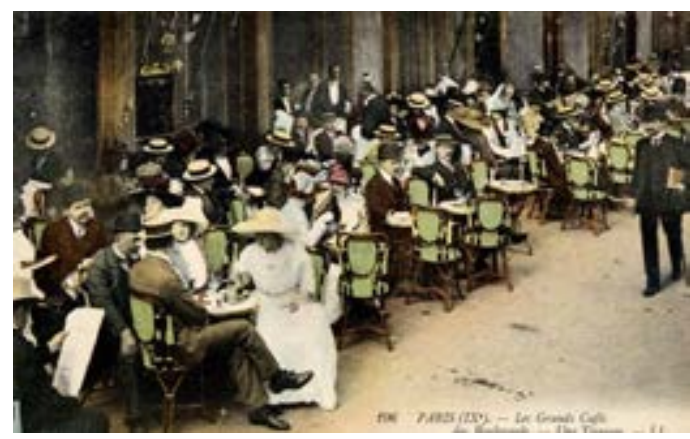

Fonte: <http://www.vitruvius.com.br/revistas/read/arquitextos/11.132/3883>.

Figura 10 - Mercado do Derby, Recife, PE, postal datado de 1904

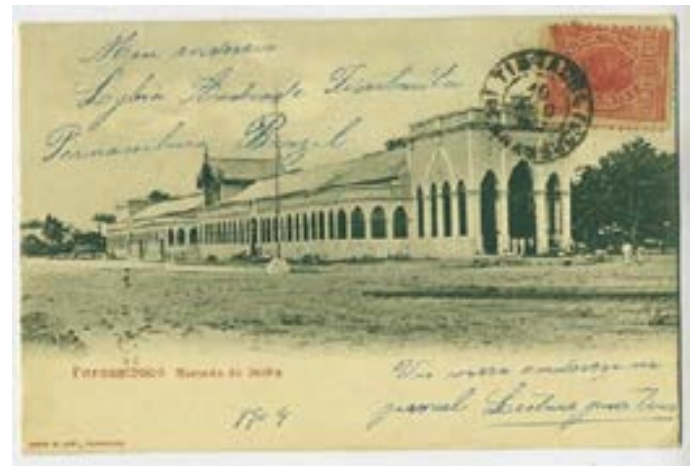

Fonte: <http://blogs.diariodepernambuco.com.br/esportes/2014/01/21/antes-do-futebol-o-mercado-do-derby/>.

A cidade torna-se protagonista de si mesma e em meio ao fascínio, luzes e lâmpadas, instala-se o fugidio, o irreal, a obra fantasmática, entre a perspectiva do progresso e sua efetivação (HARDMAN, 1988). Seus planejadores, técnicos, engenheiros, arquitetos e operários serão agentes da conexão com a nova paisagem do cosmopolitismo a ser instaurado, preconizado pelas ideias haussmanianas, que atingiam várias cidades do mundo a partir de Paris. Os olhares de engenheiros, arquitetos e literatos irão flagrar as constantes metamorfoses tentaculares dessa cidade que se oferece à ação e à tradução de seus personagens.

Estudos mais recentes procuram abordar a cidade a partir de uma perspectiva mais ampla e complexa, elencando uma série de elementos provindos de várias áreas do conhecimento. Uma formação urbana ou um aglomerado humano, para ser mais adequadamente chamado de "cidade", deveria apresentar certo conjunto de aspectos, entre os quais: 1) um determinado qualitativo populacional formado por indivíduos socialmente heterogêneos, 2) uma localização permanente, 3) uma considerável extensão espacial, 4) certo padrão de espacialidade e de organização da propriedade, 5) a ocorrência de certo padrão de convivência, 5) a identificação de um modo de vida característico dos citadinos, 6) a presença de ocupações não agrícolas, 7) a presença de um quantitativo populacional considerável, cujo limiar é redefinido a cada época da história, 8) a ocorrência de uma considerável densidade populacional, 9) uma abertura externa, 10) uma localidade de mercado, entre outras características (BARROS, 2007, p. 108). Esse conjunto de aspectos, e mais alguns outros, é que autorizariam a classificar uma formação como "cidade", conforme discussão proposta pelo autor.

A concentração de conexões e redes nas cidades pode ser usada como uma explicação da urbanização. É o acesso a certas redes que atrai pessoas. À medida que várias redes atuam juntas em uma dada área, pessoas reúnem-se em cidades. Ao mesmo tempo, essa concentração de pessoas implica a introdução de novas redes, tais como, 
conexões sociais, aumentando a criação de novas possibilidades dentro de cidades. Movimentos de urbanização social são resultado direto dessa possibilidade de fazer novas conexões. É essa abertura que faz com que as cidades sejam, ao mesmo tempo, atrativas e em certo grau também imprevisíveis.

Outro importante aspecto da aproximação moderna de cidade é perceber as divisões internas, ligadas por sua vez, às conexões externas. Como lugares de encontros históricos, as cidades são híbridas e heterogêneas. Híbridas porque as conexões que ligam lugares são múltiplas interferindo e indicando várias direções. Heterogêneas devido a sua própria dinâmica. Novos encontros são processos em movimento nos quais relações sociais e diferenças são constantemente negociadas e moldadas.

No entanto, nem as diferenças internas nem as conexões e as redes urbanas de um lugar definem, por si só, uma cidade. Como já afirmamos, as divisões internas são causadas por ligações externas, enquanto que, ao mesmo tempo, a abertura de conexões externas abre a possibilidade de novas divisões sociais. A imigração ilustra muito bem a relação entre redes externas e divisões internas. As redes concentradas no centro da cidade atraem imigrantes. À medida que eles imigram, os imigrantes trazem consigo suas próprias histórias, trazendo novas redes ou reforçando redes já existentes. Ao mesmo tempo, as histórias dos imigrantes oferecem oportunidades para identificação ou exclusão.

Maria Stella Bresciani (1998) indica os trabalhos de Raymond Williams ao analisar novas palavras e o significado de antigos vocábulos, agora ressemantizados, para o termo cidade, bem como os contrastes entre considerações positivas e negativas para as urbes modernas e seu contexto de produção.

Nesse processo de construção/destruição de referências materiais e memorialísticas no tempo e no espaço, fragmenta-se a percepção por causa da aceleração dos fenômenos e da sensibilidade a eles. Um recorte do poema abaixo tenta decifrar, ou melhor, circunscrever o que pode ser uma cidade.

Uma cidade

pode ser o nome

dum país, dum cais, um porto, um barco de andorinhas e gaivotas

ancoradas

na areia.

E pode

ser

um arco-íris à janela, um manjerico

de sol, um beijo

de magnólias

ao crepúsculo, um balão

aceso

numa noite

de junho.

Uma cidade pode ser

um coração,

um punho.

(MARTINS, 2001, p. 21).

Por outro lado, o espaço do utópico ganha dimensões até então impensáveis.

[...] E o onírico, que sobrevive nestes fragmentos de sonhos tornados realidades, exerce um elemento adicional de fascínio sobre tantos quantos o presenciem (COSTA, 1999, p. 5). 
Como exemplo, para pensarmos a ideia de sofreguidão pelo progresso e, ao mesmo tempo, a transposição de um tropos para essa realização, contribuindo para a formação de um universo simbólico relativo à ciência, tecnologia e futuro, tomamos um escritor muito lido em nossas plagas na virada do século XIX ao XX: Júlio Verne (18281905).

Em seu romance Paris no século XX, inédito até 1986, o autor projeta a capital francesa no futuro e aponta, de maneira enviesada, os aspectos da sociedade, do capital, da política e da cultura de seu tempo. Recusado pelo seu editor, Pierre Jules Hetzel, por ser excessivamente projetivo e crítico, escrito provavelmente após a publicação de Cinco semanas em um balão (janeiro de 1863), Verne lança um olhar cáustico sobre as maravilhas do século XIX e ao mesmo tempo imprime uma visão pessimista acerca das relações humanas.

A leitura da cidade e das multidões em seu trânsito reflete as modificações desse espaço pautado por outro objetivo: o dinheiro, a pressa, a pressão, a insensibilidade. Paris torna-se iluminada, mas a luz feérica não mais surpreende: integra-se à paisagem, solapada pelo "ardor americano", pelo "demônio da fortuna".

A multidão tomava as ruas; a noite começava a descer; as lojas suntuosas projetavam a distância clarões de luz elétrica; os candelabros instalados de acordo com o sistema Way, mediante a eletrização de uma rede de mercúrio, resplandeciam numa claridade incomparável; eles estavam unidos uns aos outros por fios subterrâneos; as cem mil lanternas de Paris iluminavam-se no mesmo instante, de um só golpe. O que teria dito um de nossos ancestrais ao ver aqueles bulevares iluminados com um esplendor comparável ao do sol, aqueles milhares de carros circulando sem ruído sobre o asfalto surdo das ruas, aquelas lojas ricas como palácio, de onde a luz se projetava em irradiações brancas, aquelas vias de comunicação grandes como praças, aquelas praças vastas como planícies, [...] aquelas longas galerias elegantes, aquelas pontes lançadas de uma rua à outra e, finalmente, aqueles trens cintilantes que pareciam sulcar os ares com uma rapidez fantástica? Teria ficado muito surpreendido, sem dúvida; mas os homens de 1960 já não se admiravam diante dessas maravilhas; serviam-se delas tranqüilamente, sem ficarem mais felizes por isso, pois, com seu ritmo acelerado, suas atividades apressadas, seu ardor americano, percebia-se que eram acossados sem interrupção nem piedade pelo demônio da fortuna. (VERNE, 1995, p. 48-50).

Em outro trecho, Júlio Verne analisa, com veia irrequieta, as transformações promovidas por Haussmann em sua época, especialmente às promovidas no centro de Paris, onde casas eram derribadas pelo "artista demolidor" em prol de outra estética: as avenidas e ruas ao longe.

[...] mas, na época era difícil achar onde morar numa capital pequena demais para seus cinco milhões de habitantes, à força de aumentar as praças, abrir avenidas e multiplicar os bulevares, corria-se o risco de faltar espaço para as residências particulares. O que justificava a observação da época: Em Paris não há mais casas, só ruas! Alguns bairros, inclusive, não ofereciam uma única moradia aos habitantes da $\mathrm{Ca}$ pital (VERNE, 1995, p. 88-89).

Compondo a fala de Verne, temos as fotografias realizadas por Eugene Atget 
(1857-1927), que inauguraram a fotografia urbana e registraram uma Paris fantasmagórica em suas ruas e periferias (Figura 11). Precursor da fotografia moderna em Paris, ele fotografava o vazio das ruas parisienses, a privacidade em suas vistas e os objetos inusitados. Especializou-se em vistas cotidianas e postais parisienses, pois conhecia cada canto de sua cidade natal.

Figura 11 - Rue de La Montagne, Sainte Genevieve, sem data, Eugene Atget (1857-1927)

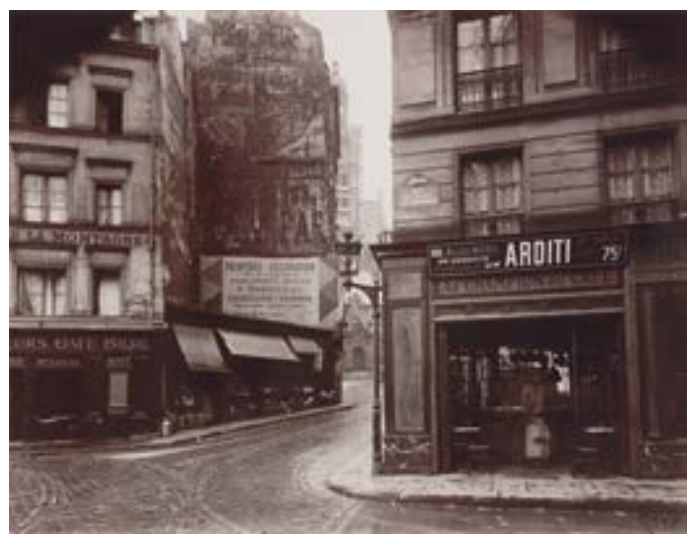

Fonte: <https://artblart.com/tag/eugene-atget-rue-de-la-montagne-sainte-genevieve/>.

Podemos considerar que a organização das referências que compõem a identidade, individual ou coletiva, esteja vinculada à ideia de pertencimento, seja esse político territorial, político ideológico ou temporal.

Entre outros autores, Ortiz (2000) afirma que a modernidade exerceu o papel de "desencaixe" das identidades, provocando a diluição de fronteiras entre os sujeitos e seus espaços, tornando esse processo, ao mesmo tempo, dinâmico e contraditório.

Bauman (2003) define para a atual sociedade a modernidade líquida como um momento em que a sociabilidade humana experimenta uma transformação que pode ser sintetizada nos seguintes processos: a metamorfose do cidadão, sujeito de direitos, em indivíduo em busca de afirmação no espaço social, a passagem de estruturas de solidariedade coletiva para as de disputa e competição, o enfraquecimento dos sistemas de proteção estatal às intempéries da vida, gerando um permanente ambiente de incerteza, a colocação da responsabilidade por eventuais fracassos no plano individual, o fim da perspectiva do planejamento em longo prazo e o divórcio e a iminente apartação total entre poder e política.

Nessa crescente (des)territorialização, as tensões entre os grupos e as tentativas de delimitação de espaços promovem ou (re) inventam tradições. Assim, o espaço transforma-se em "lugar" que, segundo Tuan, é "nossa segurança, nossa casa, nosso bairro, nossa cidade, a ele estamos unidos física e emocionalmente" (1983, p. 13).

A transformação do espaço físico em lugar afetivo recria, renova e refunda as reminiscências, as memórias de indivíduos e de grupos de famílias reinventando as redes de relações sociais e os espaços de sociabilidades nas periferias e centros das cidades.

Nesse processo, ocorre um retorno às raízes, em festas populares familiares ou comuns, em outra clave de relações. Para demonstrar essa questão, escolhemos um quadro de Anita Malfatti (1889-1964), que retrata uma festa popular brasileira: as festas juninas. Em meados de sua carreira, Anita interessa-se por temas regionalistas e volta-se às formas tradicionais, como a pintura renascentista e a arte naïf. Ela se identifica com a busca de uma pintura espontânea e bem-feita, não presa a modelos consagrados 
nem perdida no desejo de inovação. Dos anos 1940 em diante, a artista passa a pintar, cada vez mais, cenas da vida popular (Figura 12) e, nos anos 1950, o popular não é só tema, mas também passa a ser incorporado nas formas, influenciado pela arte não culta.

\section{Figura 12 - Festa de São João com guirlanda, década de 1940, óleo sobre tela $50 \mathrm{~cm} \times 61 \mathrm{~cm}$, Anita Malfatti (1889-1964)}

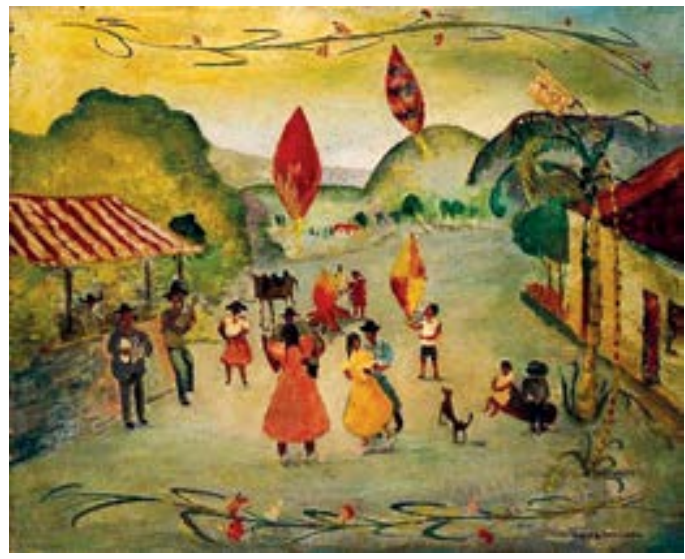

Fonte: <http://artenarede.com.br/blog/index.php/bandeirinhas-baloes-e-fogueiras-e-a-festa-junina-na-arte/>

A periferia pode ganhar contornos coloridos em telas de vários pintores, o que não significa que seja idealizado ou asséptico ou destituído de contradições e conflitos, mas um registro de certa beleza e vivacidade, como há também registros sombrios e despidos de cores, embora intensos em suas propostas.

Escolhemos o quadro de Emiliano Augusto Cavalcanti de Albuquerque e Melo (1897-1976), conhecido como Di Cavalcanti. Pintor, ilustrador, caricaturista, gravador, muralista, desenhista, jornalista, escritor e cenógrafo, inicia sua carreira artística como caricaturista e ilustrador. Na tela apresentada na Figura 13, as casas do morro são coloridas, entremeadas de árvores e de pou- cos personagens: crianças nas escadarias e negras com seus tabuleiros, embebidos em luz azulada que a tudo encampa.

Conciliando a influência das vanguardas europeias com a formulação de uma linguagem própria, Di Cavalcanti adota uma temática nacionalista e preocupa-se com a questão social, filiando-se ao Partido Comunista do Brasil, em 1928. O contato com o expressionismo, com sua ácida crítica social, e, principalmente, com a obra de George Grosz pode ser visto em vários de seus trabalhos. A vertente social e nacionalista, com temáticas ligadas ao cotidiano do povo - a favela, o malandro, o samba, os pescadores, os bares, as prostitutas e a boemia - e ambientadas no Rio de Janeiro, permanecerá constante em toda sua obra.

Figura 13 - Favela, 1958, óleo sobre tela, c.i.d. 100.00 $\mathrm{cm} \times 80.00 \mathrm{~cm}$, Emiliano Di Cavalcanti (1897-1976)

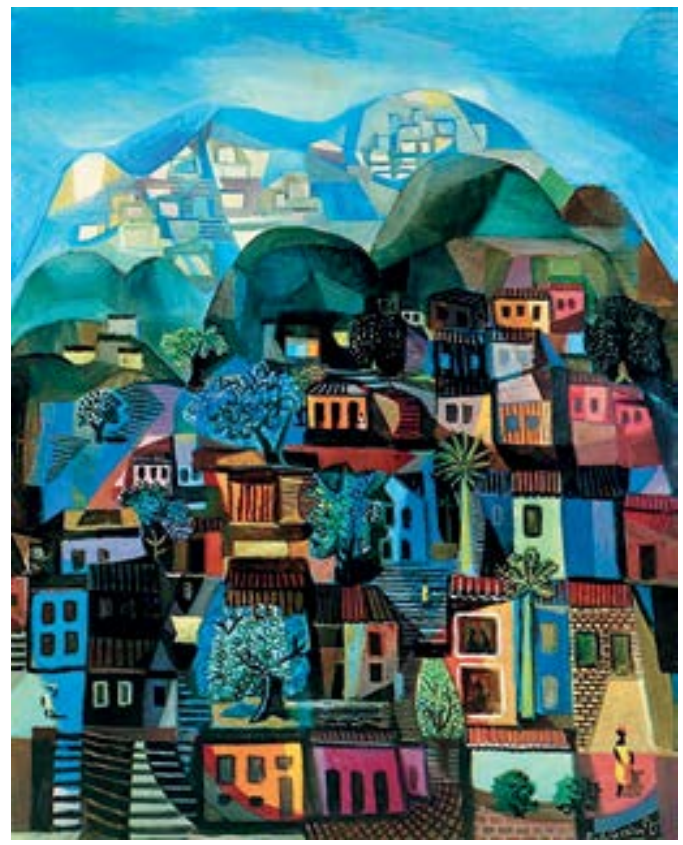

Fonte: <http://enciclopedia.itaucultural.org.br/obra4604/favela>. 
Nos desencontros das identidades, a história local transforma locais em lugares promovendo (re)aproximações, surpresas, sustos e encantamentos, pois essas sensações estão localizadas não no espaço, mas na experiência dos indivíduos com esse mesmo espaço, nas memórias eleitas para mantê-lo vivo. A memória não é única, é composta por meio de juízo de valor, separando o que deve ser lembrado e o que deve ser esquecido, relacionando-se ao sentimento de pertencimento.

Para Michael Pollak (1989), as memórias, individuais ou coletivas, são formadas a partir das conexões entre acontecimentos, personagens e lugares. Esse processo envolve a busca por reminiscências vividas pela própria pessoa ou emprestadas do grupo ao qual o indivíduo pertence. A definição de um juízo de valor ao conjunto dessas memórias estabelece o quanto ela será representativa para a compreensão do mundo ao seu redor.

Adotamos como registro da impressão do local como expressão de lugar a identificação do bairro da Liberdade, Salvador, BA, com seus habitantes e suas muitas formas de apropriação de nomes e espaços.

Há uma alternância na identificação dos habitantes: para o exterior, eles se designam como habitantes da Liberdade, conhecido na cidade como um bairro negro e proletário, populoso e animado, cativante, mas, também temeroso e, para alguns, fechado. No interior dessa primeira identificação contrastiva, outras fronteiras imaginárias, internas, são dadas pelos nomes e pelos limites de certos locais e ruas do bairro. O nome de cada setor (abrangendo, segundo o caso, 2.000 a 5.000 habitantes aproximadamente) adquire um sentido na historia específica do lugar nomeado. Por exemplo, o setor de Sieiro recebeu seu nome de um comerciante espanhol, que aí chegou no início dos anos 20 e abriu um armazém que serviu como ponto de referencia para os estrangeiros e como parada do bonde: "Armazem Sieiro". O bonde não existe mais. O armazém foi vendido por diversas vezes, depois transformado em bar e finalmente perdeu seu nome original. Mas o nome ficou para os seus arredores imediatos. Essas identidades estão muitas vezes associadas a alguns traços específicos que podem, conforme a ocasião, verter, em bem ou em mal, sobre o conjunto da Liberdade (AGIER, 1998, p. 47).

A escolha sobre o que se torna representativo é feita de forma individual, mas, também é marcada pelas ações coletivas dos grupos. Essas ações são executadas com base nas referencias selecionadas dentre um rol de possibilidades e interesses. Uma nova significação sobrepõe-se a outras mais antigas, consolidando um dado de base para a identidade do bairro: qualquer que seja o qualificativo é sempre um substrato social local, designado como sujeito, mobilizado, reunido e interpelado pelo sentimento de apego ao local, um orgulho de ser parte dele, mesmo para aqueles que puderam deixá-lo, conforme afirma Agier (1998).

A memória é uma forma de orientação, que, por intermédio de um juízo de valor adquirido, seleciona o que deve ser lembrado e o que deve ser esquecido, o que foi importante e o que não foi. Esse mesmo instrumento pode ser utilizado para o passado, mas, também, transpõe essas preferências para o presente, ou seja, se um grupo foi relegado ao esquecimento na memória 
do passado municipal (ou nacional, estadual, etc.), também não lhe é atribuído importância no presente. Assim, os repositórios de uma parcela da memória estão dispersos em arquivos, sejam escolares, familiares, oficiais ou religiosos.

Trazer à vista os fragmentos visuais que compõem esses acervos, os relatos pos- síveis inscritos nesse documento, os textos poéticos e literários e o cruzamento com outras tantas memórias, sejam orais ou escritas, é permitir montar um quebra-cabeças desses caminhos que cruzam a cidade, o que deixa escapar alguns lamentos de saudade de um tempo e local marcantes e distantes, agora somente retratos na parede.

\section{Confidência do itabirano}

Alguns anos vivi em Itabira.

Principalmente nasci em Itabira.

Por isso sou triste, orgulhoso: de ferro.

Noventa por cento de ferro nas calçadas.

Oitenta por cento de ferro nas almas.

E esse alheamento do que na vida é porosidade e comunicação.

A vontade de amar, que me paralisa o trabalho, vem de Itabira, de suas noites brancas, sem mulheres e sem horizontes.

E o hábito de sofrer, que tanto me diverte,

é doce herança itabirana.

De Itabira trouxe prendas diversas que ora te ofereço: [esta pedra de ferro, futuro aço do Brasil;] este São Benedito do velho santeiro Alfredo Duval; este couro de anta, estendido no sofá da sala de visitas; este orgulho, esta cabeça baixa...

Tive ouro, tive gado, tive fazendas.

Hoje sou funcionário público.

Itabira é apenas uma fotografia na parede.

Mas como dói!

(ANDRADE, 1978, p. 36-37).

Como toda fonte documental, as fontes visuais têm potencialidades, assim como limites e falhas. Se bem utilizadas pelos professores/pesquisadores, auxiliam a compreensão da escrita da história (e suas narrativas acerca do espaço urbano, por exemplo) e as reconstruções possíveis a partir de outros fragmentos e registros deixados pelo caminhar humano. Entrelaçados com relatos orais e escritos literários, poéticos ou científicos, as fontes visuais potencializam outro mapa (de sentidos e sensibilidades) da(s) cidade(s).

As fontes escritas literárias e poéticas propiciam ensejos líricos de memórias senti- 
mentais do lugar onde se decifra, na medida do possível, a alma da cidade.

Passados e presentes em constante reelaboração nos fazem pensar na complexidade do registro das memórias urbanas, que teimam em proporcionar outras tantas a serem decifradas, construindo cidades imateriais, utópicas, mas também reais. Cabe a seus habitantes elaborarem seus próprios mapas e constituírem pequenas bússolas de sensibilidades, compondo-se como sujeitos, usuários, flâneurs dos lugares que habitam e por onde circulam. Outras discursividades, outros caminhos, outras cidades.

\section{Abstract}

The text intends to analyze the complexity of the city concept, its transformations and appropriations made by its inhabitants and from the selection of visual and written documentation in different gaps of time and space seeking to incite perceptions of such windows as possibilities of information. Search for sensitive captures instigations came from the selected records enabling reflections about such spaces on the continuous elaboration. We circumscribe some space and time as observation capsules in order to verify the changes in the urban space and the seizure of a number of visual registers or written: Porto Alegre (RS), Paris (France), Rio de Janeiro (RJ), Salvador (BA), Feira de Santana (BA), Recife (PE), Welwyn Garden City (England) and Itabira (MG) in the late nineteenth century until the mid-twentieth century.

\section{Resumen}

El texto pretende analizar la complejidad del concepto de la ciudad, sus transformaciones y los créditos por sus habitantes y de la selección de documentos visuales y escritos en varios recortes de tiempo y espacio de búsqueda incitan a la percepción de ventanas tales como posibilidades de información. Buscar instigar las capturas sensibles de los registros seleccionados y habilitar otras reflexiones sobre estos espacios en continua reelaboración. Circunscribir algunos espacios y el tiempos como cápsulas de observación con el fin de verificar los cambios en el espacio urbano y la aprehensión de un número de registros visuales o escritas: Porto Alegre (RS), París (Francia), Río de Janeiro (RJ), Salvador (BA), Feira de Santana (BA), Recife (PE), Welwyn Garden City (Inglaterra) y Itabira (MG) a finales del siglo XIX hasta mediados del siglo XX.

Palabras clave: Ciudad. Registros. Sensibilidades.

\section{Referências}

AGIER, Michel. Lugares e redes - as mediações da cultura urbana. In: NIEMEYER, Ana Maria; GODOI, Emilia Pietrafesa de (Org.). Além dos territórios. Campinas: Mercado de Letras, 1998. p. 41-64.

ANDRADE, Carlos Drummond de. Antologia Poética. 12. ed. Rio de Janeiro: José Olympio, 1978.

BARROS, José D'Assunção. Cidade e história. Petrópolis: Vozes, 2007.

Keywords: City. Records. Sensitivities. 
BAUMAN, Zygmunt. Modernidade líquida. Tradução de Plínio Dentzien. Rio de Janeiro: Zahar, 2003.

BENJAMIN, Walter. Obras escolhidas: magia e técnica, arte e política: ensaios sobre literatura e história da cultura. São Paulo: Brasiliense, 1996.

BRESCIANI, Maria Stella M. História e historiografia das cidades, um percurso. In: FREITAS, Marcos Cezar de (Org.). Historiografia brasileira em perspectiva. São Paulo: Contexto, 1998. p. 237-258.

CHOAY, Françoise. O urbanismo: utopias e realidades. Uma antologia. São Paulo: Perspectiva, 1992.

COSTA, Vidal A. de Azevedo. Visões ascendentes: fragmentos do olhar curitibano ao mais leve que o ar. Curitiba: Aos Quatro Ventos, 1999.

DEPAULE, Jean Charles; TOPALOV, Christian. A cidade através de suas palavras. In: BRESCIANI, Maria Stella (Org.). Palavras da cidade. Porto Alegre: Editora Ufrgs, 2001.

DIDI-HUBERMAN, Georges. O que vemos, o que nos olha. São Paulo: Editora 34, 1998. 260 p.

FRANCO, Patrícia dos Santos. Cartões-postais: fragmentos de lugares, pessoas e percepções. Métis: História \& Cultura, Caxias do Sul, v. 5, n. 9, p. 25-62, jan./jun. 2006.

HARDMAN Francisco Foot. Trem fantasma. A modernidade na selva. São Paulo: Cia das Letras, 1988.

MARTINS, Albano Martins. Castália e outros poemas. Porto: Campo das Letras, 2001.

OLIVEIRA, Lucia Lippi. Cultura urbana no Rio de Janeiro. In: FERREIRA, Marieta M (Coord.). Rio de Janeiro: uma cidade na História. Rio de Janeiro: FGV, 2000. p. 139-150

ORTIZ, Renato. Cultura e modernidade na França no século XIX. São Paulo: Brasiliense, 2000.

OSTERMANN, Érika. Imagem urbana: percepção e devaneio. In: MACHADO, Denise B.
P.; VASCONCELOS, Eduardo M. de (Org.). Cidade e imaginação. Rio de Janeiro: UFRJ, FAU, PROURB, 1996. p. 157-164.

PESAVENTO, Sandra Jatahy (Coord.). O espetáculo da rua. Porto Alegre: Editora Ufrgs, 1996.

POLLAK, Michael. Memória, esquecimento, silêncio. Estudos Históricos, Rio de Janeiro, v. 2, n. 3, p. 3-15, 1989.

QUINTANA, Mario. Apontamentos de história sobrenatural. Rio de Janeiro: Objetiva, 2012.

REGO, Renato Leão. O desenho urbano de Maringá e a idéia de cidade-jardim. Acta Scientiarum, Maringá, v. 23, n. 6, p. 1569-1577, 2001.

RONCAYOLO, Marcel. Cidade. In: ENCICLOPÉDIA Einaudi. Lisboa: Imprensa Nacional - Casa da Moeda, 1986. p. 411-422.

ROUILLÉ, Andre. A fotografia: entre documento e arte contemporânea. São Paulo: Senac, 2009.

SAMAIN, Etienne (Org.). O fotográfico. 2. ed. São Paulo: Hucitec; Senac, 2005.

SIMMEL, Georg. Metrópole e a vida mental. Tradução de Sergio Marques dos Reis. In: VELHO, Otavio (Org.). O fenômeno urbano. Rio de Janeiro: Zahar, 1973. p. 11-25.

TUAN, Yi-Fu. Espaço e lugar: a perspectiva da experiência. São Paulo: Difel, 1983.

VASCONCELOS, Pedro A. Dois séculos de pensamento sobre a cidade. Ilhéus: Editus, 1999.

VERNE, Júlio. Paris no século XX. Tradução de Heloisa Jahan. São Paulo: Ática, 1995. 